\title{
Effects of Political Disintegratin on Foreign Capital Requirement During Transition
}

\author{
Swapan Sen* \\ Michigan Technological University \\ Sergei Beloborodov \\ Michigan Technological University
}

\begin{abstract}
Political disintegration of a country leads to abrupt severance of existing economic ties. Internal trade flows between the regions of an undivided country become foreign trade after disintegration. The newly independent states, during their transition from political sovereignty to economic self-reliance, may find the reorientation of their economies through foreign trade particularly difficult. The adverse consequences of partition may have to be contained, at least temporarily, with the help of foreign capital. The foreign capital requirement of the newly independent countries in that case will depend on the degree of incomplete product line inherited by each of them and the post-partition level of economic cooperation among themselves. Given average success in cooperation, it is concluded that the need will be larger (and more volatile) for the countries which inherit higher degrees of incomplete product line. (JEL Classification: F15, 052)
\end{abstract}

\section{Introduction}

Plants and factories required to produce a finished good in various stages of its production, organize a product line. Product lines can be located fully

* Correspondence Address: Michigan Technological University, School of Business and Engineering Administration, Houghton, MI 49931, U.S.A.; Tel: (906) 487-3105, Fax: (906) 487-2944; E-mail: seswapan@mtu.edu.

C1996 - Institute for International Economics, Sejong Institution. All rights reserved. 
or partly in a single territory (a region, republic, city or village). A product line that is partly located in a single territory is an incomplete product line for that territory. ${ }^{1}$ In a country, the production facilities of a single product are often spread over many regions. This creates economic complementarities among regions. Political disintegration severs these economic relationships among the regions and results in many states inheriting various degrees of incomplete product line in their territories and contribute to the economic decline of these states in the immediate post disintegration period. ${ }^{2}$

The internal trade flows within the undivided country become foreign trade after disintegration. The former regions can address the problems posed by incomplete product lines by trading among themselves. During the period of transition, however, reorientation of production and marketing through foreign trade and other market mechanisms becomes particularly difficult. Trade may be impeded by the break-down of the currency and payment system. ${ }^{3}$ Thus the adverse consequences of partition may have to be contained, at least temporarily, with the help of foreign capital. Foreign capital requirement (standard) of the newly independent countries would then depend on the degree of incomplete product line inherited by each of them. ${ }^{4}$

1. Consider, for example, the case of the former Soviet truck industry. If the engine production facility was located in Russia and all other parts such as tiers and body assemblies were produced in Kazakhstan, then after the partition, both Russia and Kazakhstan inherit an incomplete product line. If, on the other hand, all production facilities required in the manufacturing of trucks were located in Kazakhstan, then Kazakhstan would have inherited a complete product line.

2. The adverse economic consequences of the recent political disintegration of the former Soviet Union is evident. 〈See, for example, Noren and Watson [1992]). The economic decline cannot, however, be fully attributed to the bottlenecks created by political separation alone. Also, to the extent the old system was exhausted and depleted, the partition will present opportunities for rebuilding and renovation.

3. In the case of the former soviet republics, the break down of the ruble zone and the need for hard currency earnings led to unsuccessful attempts at directing trade to western countries rather than among themselves. During the transition years of 1990-93, trade among the republics and trade with the rest of the world collapsed to less than one-third of trade in 1990 〈Michalopoulos and Tar [1994], Chapter 1).

4. Clearly, this does not imply that foreign capital requirement will be determined solely by the degree of incomplete product line. Factors such as the effectiveness of market reform, the progress of privatization and prospect for political stability will influence the demand for foreign capital and most certainly, the decisions of the lenders and donors. 
The level of economic cooperation among the regions in the post-partition period will also influence this outcome.

This paper presents a simple model for examining economic effects of political disintegration and concludes that given average success in cooperation, the need for foreign capital will be larger (and more volatile) for countries which inherit higher degrees of incomplete product line. This outcome will be influenced by the economic cooperation between the regions in the post-disintegration period. Section II presents the model for determining foreign capital requirement during transition. An empirical examination of the model in the context of the recent disintegration of the former Soviet Union is presented in Section III. Conclusions are summarized in Section IV.

\section{The Model}

Income is the sum of income from complete product line (Income C) and income from incomplete product line (Income I). Writing 0 for time before partition and $t$ for time after partition, we define:

$$
\begin{aligned}
& \text { Income }(0)=\text { Income } C(0)+\operatorname{Income} I(0) \\
& \text { Income }(t)=\text { Income } C(t)+\operatorname{Income} I(t)
\end{aligned}
$$

Assuming that partition of the country will affect income from incomplete product lines but not income from complete product lines, income after partition can be expressed as:

$$
\begin{aligned}
& \text { Income } C(t)=\text { Income } C(0) \\
& \text { Income } I(t)=(\alpha) \text { Income } I(0)
\end{aligned}
$$

where $0 \leq \alpha \leq 1$ is a random variable determined by economic policy after partition.

Income refers to the gross value of goods and services obtained from the interrupted enterprise. Net income is the value of goods and services produced less the value of goods and services required to maintain the existing stock of resources. As long as resources freed up from the interrupted enterprise can be equally productive elsewhere, net income is what is lost due to disintegration. However, relocation of resources during the transition 
poses problems and losses due to disintegration can exceed net income. External shocks are likely to accentuate internal market frictions and the loss of income due to political disintegration can be so severe that the entire gross income will be at risk. There may be relative price changes following disintegration. Benefits from price liberalization are likely to be uneven across industries and the interrupted enterprises are less likely to benefit from such price changes. In the transition context, therefore, gross income appears to be the most suitable notion of income from an enterprise. If narrower notions of income such as net income or value added ${ }^{5}$ are applied, the value of $\alpha$ would likely be smaller.

Let $y=\frac{\text { Income } I(0)}{\text { Income }(0)}$ be the proportion of income from incomplete product line that is historically given for each state and cannot be affected by current economic policy. Thus $(1-y)$ is the proportion of income from complete product lines. Equation (2) now becomes:

$$
\begin{aligned}
& \text { Income }(t)=\text { Income } C(0)+\alpha \text { Income } I(0) \\
& =(1-y) \text { Income }(0)+\alpha y \text { Income }(0)
\end{aligned}
$$

We assume that the shrinkage in income due to disintegration must be compensated by ForeignCapital which can be direct foreign investment and/or foreign debt. Then,

$$
\text { ForeignCapital }(t)=\operatorname{Income}(0)-\operatorname{Income}(t)
$$

Thus we ignore foreign trade during transition and assume that there was no foreign capital initially. ${ }^{6}$ By using (5), (6) becomes

$$
\text { ForeignCapital }(t)=(1-\alpha) \text { y Income }(0)
$$

Expressing ForeignCapital $(t)=F(\alpha)$, the expected value of foreign capital can be written as:

5. Value added is what the firm has available for paying taxes and remuneration for its factors of production.

6. We ignore foreign trade for the difficulties of utilizing trade during the transition period, as described before. The assumption of zero initial foreign capital is made for reasons of expositional simplicity. 


$$
E(F(\alpha))=\frac{\int F(\alpha) \rho(\alpha) d \alpha}{\int \rho(\alpha) d \alpha}
$$

where $F(\alpha)$ is a function of the random variable $\alpha$ and $\rho(\alpha)$ is a density function. Similarly, the variance of $F(\alpha)$ is given by:

$$
\operatorname{Var}(F(\alpha))=\frac{\int[F(\alpha)-E(F(\alpha))]^{2} \rho(\alpha) d(\alpha)}{\int \rho(\alpha) d(\alpha)}
$$

Considering a density function $\rho(\alpha)=1$ so that $\alpha$ would take values from 0 to 1 with uniform probability, the expected value and the variance of foreign capital becomes:

$$
\begin{aligned}
& \text { E }(\text { ForeignCapital })=\frac{1}{2} y \text { Income }(0) \\
& \operatorname{Var}(\text { ForeignCapital })=\frac{1}{12} y^{2} \text { Income }(0)^{2}
\end{aligned}
$$

Implicitly assuming identical credit risk for all republics before and after disintegration, a comparison of the expected value and the variance of ForeignCapital for two countries, 1 and 2 with $y_{1}$ and $y_{2}$ percent of income from incomplete product lines, respectively, where $y_{1}>y_{2}$, and the two countries are identical otherwise, shows that

$$
E(F(\alpha))_{1}>E(F(\alpha))_{2}
$$

and that

$$
\operatorname{Var} E(F(\alpha))_{1}>\operatorname{Var} E(F(\alpha))_{2}
$$

Thus, a state which inherits a larger proportion of incomplete product lines is expected to require a larger (and more volatile) magnitude of foreign capital during transition.

The above result is qualified by the particular density function chosen, namely, $\rho(\alpha)=1$. This density function represents the case of average level of co-operation between the former republics. We consider below two other types of density functions:

(i) $\rho(\alpha)=\alpha^{n}$; the case of high degree of co-operation, and

(ii) $\rho(\alpha)=(1-\alpha)^{n}$, the case of low degree of co-operation. Here, $n$ is any positive integer. 
In the case (i), as $n \rightarrow \infty$, the probability of $\alpha$ taking on a value equal to 1 tends towards unity and the expected value of foreign capital tends toward zero. Thus, higher the degree of cooperation, lower is the need for foreigncapital. In the case (ii), as $n \rightarrow \infty$, the expected value of foreign capital tends toward $y$ Income (0) or toward Income I(0). This means that if a state obtained $10 \%$ of its income from incomplete product lines before partition, its expected foreign capital to GDP ratio after partition will be 0.10 .

In summary, foreign capital requirement during transition depends on incomplete product line and cooperation among the regions. Given, average success in cooperation, countries with higher incomplete product lines will have higher need for foreign capital. ${ }^{7}$

\section{A. The Relationship Between Foreign Capital and Incomplete Product Line - A Graphical Presentation}

Figure 1 shows the relationship between expected foreign capital to GDP ratio and incomplete product line. This relationship is linear. The slope is determined by the density function. For a density function $\rho(\alpha)=1$, the slope $=\frac{1}{2}$, meaning that a $1 \%$ higher value of $y$ will increase the proportion of foreign capital in national income by $0.5 \%$. If $\rho(\alpha)=\alpha^{n}$, the slope is $\frac{1}{n+2}$. In other words, in the case of high degree of co-operation, the slope of the line will be less steep indicating lower need for foreign capital. If $\rho(\alpha)=(1-\alpha)^{n}$, the case of low degree of cooperation, the slope $\left(=\frac{n+1}{n+2}\right)$ will be greater and larger amount of foreign capital will be needed.

It is, however, possible that two states with different proportions of income from incomplete product lines, will have the same expected need for foreign capital because of their having different density functions (different

7. A parallel result follows with respect to the exchange value of national currencies of the republics; namely, countries with higher degree of incomplete product line will have a weaker and a more volatile national currency. This result obtains because the exchange rate, in the absence of foreign trade, depends on foreign capital and hence on incomplete product line:

$\Delta$ ExchangeRate $=k(1-\alpha) y$ Income $(0)$

where $k$ is a factor of proportionality. This proposition is the subject of a separate investigation. 
Figure 1

Relationship Between Debt Ratio $\boldsymbol{F}(\alpha)$ and Incomplete Product Line (y)

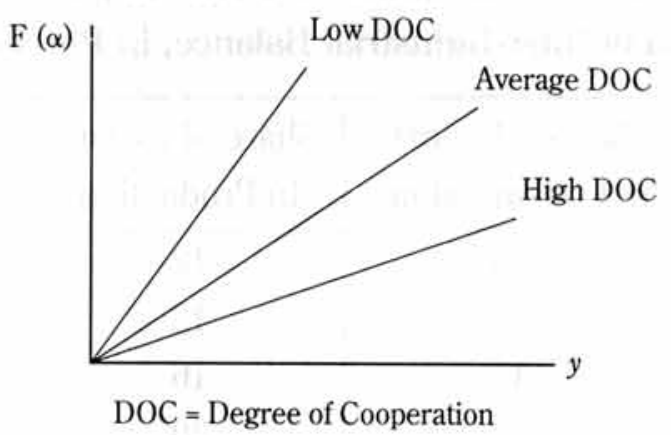

probability of a policy decision being made). This shows the role of postindependence economic policy.

\section{The Case of the Former Soviet Union - An Empirical Examination}

In the former soviet union, production facilities of a single product was spread over many regions. This was done deliberately for political and military considerations [Nove, 1980]. Orlowski [1993] notes that Soviet economic policy sought to improve regional balance among its diverse republics by means of fiscal redistribution between the center and the republics and by means of inter-republican trade flows. In our view the socialist policy toward industrial location had similar objective: it created economic interdependence among the republics by spreading the production facilities of a single product over many republics of the former Soviet union. This interdependence has now been interrupted by political disintegration. Negative income shocks generated from disruptions in trade, the break-down of fiscal transfers and the collapse of the ruble zone 〈Michalopoulos [1993], Michalopoulos and Tarr (ed.) [1994]). Our observation is that the disintegration resulted in many states inheriting various degrees of incomplete product line in their territories. Such interruptions in production contributed to the post-independence economic decline of the states and can serve as a basis for determining the standard of foreign capital requirement of these states. 
Table 1

Specific Proportion of Import and Export in Total Volume of Production and Consumption for Soviet Republics in 1988 (Data of Inter-Industrial Balance, in Percent)

\begin{tabular}{|l|c|c|c|}
\hline & $\begin{array}{c}\text { Share of Import } \\
\text { In Consumption }\end{array}$ & $\begin{array}{c}\text { Share of Export } \\
\text { In Production }\end{array}$ & $(2)+(3)$ \\
\hline Russia & 15 & 12 & 27 \\
Kazakhstan & 19 & 12 & 31 \\
Ukraine & 17 & 16 & 33 \\
Uzbekistan & 22 & 20 & 42 \\
Kyrgystan & 26 & 19 & 45 \\
Turkmanistan & 24 & 22 & 46 \\
Tajikistan & 27 & 20 & 47 \\
Azerbaidjan & 22 & 26 & 48 \\
Lithuania & 27 & 22 & 49 \\
Latvia & 27 & 24 & 51 \\
Belarus & 25 & 27 & 52 \\
Moldova & 28 & 25 & 53 \\
Estonia & 29 & 24 & 53 \\
Georgia & 28 & 26 & 54 \\
Armenia & 31 & 26 & 57 \\
\hline
\end{tabular}

Note: Rather than finding the ratios directly from data on consumption and production, the two ratios are added in the last column because data on the proportions only were available.

Source: GOSKOMSTAT the USSR, USSR in Numbers in 1989, p. 24, Moscow, 1990.

For an empirical estimation of the degree of incomplete product line, $y$, for the former Soviet republics, we consider data on proportions of production and consumption exported and imported in the total volume of production and consumption for the Soviet republics in 1988, when all republics were integrated in a joint economic system. The data are presented in Table 1. We consider the sum of exports and imports as the relevant indicator of inter-republican interdependence and sort them in ascending order.

Three distinct groups of republics emerge. Republics such as the Russian Federation, Kazakhstan and Ukraine; the largest economies of the former 
Table 2

Observed and Predicted Debt Ratios for

the Former Soviet Republics, 1993

\begin{tabular}{|l|c|c|c|c|}
\hline & $\begin{array}{c}\text { 1993GDP } \\
\text { (US \$ Million) }\end{array}$ & $\begin{array}{c}\text { 1993DEBT } \\
\text { (Observed) }\end{array}$ & $\begin{array}{c}\text { DEBT-RATIO } \\
\text { (Predicted) }\end{array}$ & DEBT-RATIO \\
\hline Armenia & 2190 & 140 & $6.39 \%$ & $6.84 \%$ \\
Azerbaizan & 4992 & 35.5 & 0.71 & 5.76 \\
Belaruse & 27545 & 960.7 & 3.49 & 6.24 \\
Estonia & 5092 & 154.8 & 3.04 & 6.36 \\
Georgia & 2994 & 568 & 18.97 & 6.48 \\
Kazakstan & 24728 & 1639.6 & 6.63 & 3.72 \\
Kyrgyz & 3915 & 308.4 & 7.88 & 5.40 \\
Latvia & 4602 & 231 & 5.02 & 6.12 \\
Lithuania & 4335 & 291.1 & 6.72 & 5.88 \\
Moldova & 4292 & 289 & 6.73 & 6.36 \\
Tajikistan & 2520 & 41.5 & 1.65 & 5.64 \\
Uzbekistan & 20425 & 739.3 & 3.62 & 5.04 \\
Ukraine & 109079 & 3554.9 & 3.26 & 3.96 \\
Russia & 329432 & 83089.2 & 25.22 & $*$ \\
\hline
\end{tabular}

Note: * Russia was not included in the regression.

Source: World Bank, 1994, and 1995.

Soviet Union, have relatively low inter-republic trade flows indicating a low degree of incomplete product line. The Asian republics of Uzbekistan, Kyrgystan, Turkmenistan, Takdzhikstan and Aizerbaidzhan; traditional exporters of natural resources and semi-finished goods follow next. Smaller republics such as Lithuania, Latvia, Belarus, Maldova, Estonia, Georgia and Armenia, that did not produce natural resources and were specialized to assemble final products are at the bottom of the list, implying a high degree of incomplete product lines in those states.

Although data presented here are imperfect proxies for incomplete product lines, they allow a ranking of the former soviet republics in order of the degree of incomplete product lines inherited by them. Availability of data on debt and GDP of the republics is limited. Debt and GDP data on 14 of the 15 
republics for the year 1993 are reported in World Bank [1994 and 1995] and are shown in Table 2. Simple regression of debt ratio on the degree of incomplete product line results as follows:

$$
\begin{aligned}
& \text { ForeignDebt }=\underset{(4.7108)^{*}}{.0012 y} \quad R^{2}=0.052 ; \quad n=13 \\
& { }^{\star} t \text {-value; significant at } 1 \% .
\end{aligned}
$$

The coefficient of $y$ appears highly significant although the overall explanatory power of the regression is limited $\left(R^{2}=0.052\right)$. The latter is possibly the result of exclusion of other relevant determinants of debt ratios. Because the model assumes zero initial debt, the regression was performed suppressing the intercept. As Russia absorbed the existing debts of all other republics, it was excluded in the regression. Note that data on $y$ pertain to 1988 (the year before the disintegration began) and data on debt ratio pertain to 1993 (the earliest debt ratios available). ${ }^{8}$ Table 2 shows the actual and predicted debt ratios for each republic. Prediction errors do not appear significant except for Georgia.

\section{Concluding Observations}

This paper examined the economic effects of political disintegration on newly independent states during their transition from political sovereignty to economic self-reliance. Before disintegration, product lines are spread over many regions in the joint country. After disintegration, linkages in production are interrupted as states inherit incomplete product lines and suffer income losses. Political disintegration generates negative income shocks due to the break down of foreign trade, fiscal transfers and payment systems. Under the restrictive assumption that the loss of income due to political disintegration will have to be met by foreign capital, the need for foreign

8. Debt ratios are obtained from World Bank [1994 and 1995]. Availability of debt ratios for the year 1992 are rudimentary and do not show any significant relationship. Using data presented in Michalopoulos and Tarr [1994, Table 1.8, p.15] on 1990 share of intraregional trade of the republics as a proxy for $y$, produces similar regression results: Foreign Debt $=.00065 y$. The coefficient has a $t$-value $(=4.4816)$ which is significant at $1 \%$. 
capital is found to be higher and more volatile for republics which derived a higher portion of their pre-disintegration income from incomplete product lines. This scenario is based on the assumption that the attempt at economic co-operation among the newly independent states will achieve only average success. It is possible that the historical legacy of inheriting incomplete product lines can be partially overcome by economic cooperation in the post-independence era. Limited empirical examination in the context of the former Soviet Union shows that the degree of incomplete product line is a significant determinant of debt ratios of newly independent former republics.

\section{References}

Goskomstat [1990], USSR in Numbers in 1989, p. 24; Moscow.

Michalopoulos, Constantine [1993], Trade Issues in the New Independent States. Series on Studies of Economies in Transformation No. 7, World Bank; Washington DC.

Michalopoulos, C. and David Tarr, (Editors) [1994], Trade in the New Independent States, Series on Studies of Economies in Transformation No. 13, World Bank; Washington DC.

Nove, Alec [1980], Soviet Economic System, George Allen and Unwin Ltd.; London.

Noren, James and Robin Watson [1992], "Interrepublican Economic Relations After the Disintegration of the USSR," Soviet Economy, 8(2), April-June.

Orlowski, Lucjan T. [1993], "Indirect Transfer in Trade Among Former Soviet Union Republics: Sources, Patterns and Policy Responses in the Post-Soviet Period," Europe-Asia Studies, 45(6); pp. 1001-1024.

World Bank [1994], Trends in Developing Economies; Washington DC.

World Bank [1995], World Tables; Washington DC. 